\title{
Microcephaly-complex motor and sensory axonal neuropathy syndrome
}

INSERM

\section{Source}

INSERM. (1999). Orphanet: an online rare disease and orphan drug data base. Microcephaly-complex motor and sensory axonal neuropathy syndrome.

ORPHA:423894

Microcephaly-complex motor and sensory axonal neuropathy syndrome is an extremely rare subtype of hereditary motor and sensory neuropathy characterized by severe, rapidly-progressing, distal, symmetric polyneuropathy and microcephaly (which can be evident in utero) with intact cognition. Clinically it presents with delayed motor development, hypotonia, absent or reduced deep tendon reflexes, prog ressive muscle wasting and weakness and scoliosis. 